10

\title{
Влияние протонного облучения на свойства стекла с покрытием ITO
}

\author{
(C) Р.Х. Хасаншин ${ }^{1,2}$, Л.С. Новиков ${ }^{3,4}$ \\ ${ }^{1}$ Акционерное общество „Композит“, \\ 141070 Королев, Московской обл., Россия \\ ${ }^{2}$ МГТУ им. Н.Э. Баумана, \\ 111111 Москва, Россия \\ ${ }^{3}$ Московский государственный университет им. М.В. Ломоносова, НИИ ядерной фризики имени Д.В. Скобельцына, \\ 119991 Москва, Россия \\ ${ }^{4}$ Национальный исследовательский университет „Высшая школа экономики“, \\ 101000 Москва, Россия \\ e-mail: rhkhas@mail.ru
}

Поступила в редакцию 06.02.2019 г.

В окончательной редакции 06.02.2019 г.

Принята к публикации 18.07.2019 г.

Исследованы изменения морфологии поверхностей и оптических свойств образцов стекла К208 с пленкой ITO в результате воздействия протонов с энергией $20 \mathrm{keV}$ и дозой $0.2-1.0 \mathrm{mC} / \mathrm{cm}^{2}$ при плотности протонного тока $9 \mathrm{nA} / \mathrm{cm}^{2}$. Экспериментально показано, что наличие пленки ITO влияет на характер изменения морфологии и является основной причиной деградации оптических свойств образцов при протонном облучении.

Ключевые слова: спектр отражения, атомно-силовая микроскопия, немостиковый кислород, микровыступы.

DOI: $10.21883 /$ OS.2019.11.48521.49-19

\section{Введение}

Воздействие заряженных частиц на стекла сопровождается генерацией в них радиационных центров окраски (ЦО), аккумулированием объемных зарядов, обуславливающих электрические поля, которые приводят к возникновению электростатических разрядов (ЭСР) [1-5], изменениями стехиометрии и структуры материалов и другими процессами [6-9]. Исследование радиационностимулированных процессов в стеклах представляет значительный интерес как с научной точки зрения, так и для создания новых материалов [10,11] и решения актуальных задач космического материаловедения. Например, взаимодействие высокоорбитальных спутников Земли с горячей магнитосферной плазмой (ГМП), особенно во время геомагнитных бурь, сопровождается рядом явлений, негативно влияющих на функционирование спутников. В частности, возникновение радиационных ЦО и ЭСР приводят к деградации оптических свойств терморегулирующих покрытий (ТРП) класса „солнечные отражатели“ и покровных стекол солнечных батарей, и как следствие, к повышению температуры спутников в первом случае и к снижению мощности солнечных батарей во втором. Для уменьшения вероятности возникновения ЭСР на солнечных батареях и терморадиаторах спутников на покровные стекла и элементы ТРП методом магнетронного распыления наносят проводящую пленку оксида индия-олова (Indium tin oxide или ITO) $[12,13]$.

Известно, что основными компонентами ГМП являются электроны и протоны. При этом до настоящего времени практически отсутствуют сведения о стойкости пленки ITO к воздействию не только ГМП, но и протонов с энергиями, характерными для ГМП. В работе [14] показано, что пленки ITO на стеклянных подложках стойки к облучению протонами с энергией $100 \mathrm{keV}$ при дозах до $1.6 \mathrm{mC} / \mathrm{cm}^{2}$. Однако доля частиц с энергией $100 \mathrm{keV}$ в спектре протонов ГМП незначительна, а основной вклад в него вносят протоны с более низкими энергиями [15].

В настоящей работе исследуются изменения свойств стекла К208 с пленкой ITO и отражающим покрытием под действием протонов с энергией $20 \mathrm{keV}$, характерной для энергетического спектра частиц ГМП. Полученные результаты дают новую информацию для понимания процессов, протекающих при воздействии ГМП на стекла, и для прогнозирования возможных негативных явлений, связанных с использованием пленок ITO в качестве проводящего покрытия на оптических материалах спутников.

\section{Методика эксперимента}

В экспериментах использовались образцы двух типов, изготовленных на основе стеклянных пластин, полученных вытягиванием через валки из расплава стекла К208, имеющего следующий состав (мол. \%): $\mathrm{SiO}_{2}(69.5) ; \mathrm{CeO}_{2}$ (2.0); $\mathrm{B}_{2} \mathrm{O}_{3}$ (11.93); $\mathrm{K}_{2} \mathrm{O}$ (6.25); $\mathrm{Na}_{2} \mathrm{O}$ (10.33). На одну из поверхностей всех образцов, как и на ТРП класса „солнечный отражатель“, методом магнетронного напыления последовательно нанесены слои серебра и нержавеющей стали толщиной около 0.1 и $0.2 \mu \mathrm{m}$ соответственно [16]. 
У образцов 1-го типа одна поверхность стекла оставалась свободной, а на стеклянную поверхность образцов 2-го типа магнетронным методом нанесена пленка ITO толщиной до $0.08 \mu \mathrm{m}$.

Образцы в виде квадратных пластин $40 \times 40 \mathrm{~mm}$ толщиной $170 \pm 1 \mu \mathrm{m}$ металлизированной стороной прикрепляли к полированной поверхности металлического термостатированного столика автоматизированного стенда УВ-1/2 АО „Композит“. Облучение протонами проводилось при следующих условиях:

- давление в вакуумной камере $10.4 \mathrm{~Pa}$;

- энергия протонов $20 \mathrm{keV}$;

- плотность протонного тока $9 \mathrm{nA} / \mathrm{cm}^{2}$;

- температура столика составляла $24 \pm 1^{\circ} \mathrm{C}$.

Исследовались четыре партии образцов каждого типа, которые были пронумерованы в порядке возрастания дозы облучения: № $1-0.2 \mathrm{mC} / \mathrm{cm}^{2}$; № $2-0.4 \mathrm{mC} / \mathrm{cm}^{2}$; № $3-0.6 \mathrm{mC} / \mathrm{cm}^{2}$; № $4-1.0 \mathrm{mC} / \mathrm{cm}^{2}$.

Поверхности исходных и облученных образцов исследовали с помощью атомно-силового микроскопа (АСM) с использованием полуконтактной атомно-силовой моды. Спектральные коэффициенты отражения образцов в диапазоне длин волн (200-2500) nm регистрировались с помощью двулучевого спектрофотометра.

\section{Результаты экспериментов и их обсуждение}

Протоны с энергиями, характерными для ГМП, при взаимодействии со стеклом расходуют энергию на ионизацию атомов и возбуждение электронной подсистемы, что ведет в конечном итоге к их термализации и захвату соответствующим ловушками. Глубина проникновения протонов, рассчитанная методом Монте-Карло, в образцы 1-го и 2-го типа составляет соответственно около 0.38 и $0.35 \mu \mathrm{m}$. Следовательно, в тонком приповерхностном слое образцов формируется область локализации положительного заряда, создающего электрическое поле, которое индуцирует на поверхности серебряной пленки отрицательный заряд.

На рис. 1 приводятся АСМ-изображения фрагментов поверхностей облученных образцов 1-го (рис. 1,a) и 2-го (рис. $1, b)$ типа из партии № 1. Из рисунка видно, что в результате облучения на поверхностях образцов образовались микровыступы, которые представляют собой газонаполненные пузырьки. При этом средние значения их высоты $(1, \mathrm{c})$ и количество на единице поверхности для образцов 1-го типа приблизительно в два раза больше, чем для образцов 2-го типа.

Известно, что непрерывность в сетке стекла К208 нарушается из-за наличия в его структуре концевых группировок $\equiv \mathrm{SiO}^{-} \ldots \mathrm{Na}^{+}\left(\mathrm{K}^{+}\right)$с атомами немостикового кислорода в середине. В процессе облучения в стекле происходит перераспределение натрия, полевая миграция ионов $\left(\mathrm{Na}^{+}\right)$которого играет ключевую роль в перестройке микроструктуры стекла и высвобождении атомов немостикового кислорода.

Согласно данным работ $[17,18]$ подвижность ионов водорода на три порядка ниже, чем ионов натрия, что, в частности, объясняется тем, что ионы водорода встраиваются в микроструктуру стекла $[19,20]$ или захватываются ловушками. Ионы $\mathrm{Na}^{+}$мигрируют из области локализации протонов как в направлении к облучаемой поверхности, так и к серебряной пленке. Воздействие протонов увеличивает энергии и, соответственно, амплитуды колебаний атомов в облучаемом слое стекла, что стимулирует как миграцию ионов натрия и их десорбцию с облучаемой поверхности в случае образцов 1-го типа [21], так и подвижность освободившихся при этом немостиковых атомов кислорода. Миграция этих атомов и их агрегация в кластеры в окрестностях точечных дефектов приводит к образованию микровыступов - молекулярных пузырьков в приповерхностном слое стекла, облучаемом электронами или ионами [2224], что и подтвердили результаты наших экспериментов.

Разница в количестве и размерах микровыступов на поверхности облученных образцов 1-го и 2-го типа объясняется следующими причинами. В первом случае вся энергия протонов выделяется в стекле и микровыступы образуются на свободной поверхности, а во втором протоны после прохождения пленки ITO попадают в стекло с энергией около $12 \mathrm{keV}$ и микровыступы образуются на его поверхности под пленкой ITO, являющейся дополнительным препятствием для роста микровыступов.

В партии № 2 отношения количества и средней высоты микровыступов на поверхности образцов 1-го и 2-го типов составили соответственно приблизительно $2.1: 1$ и 1.3:1. Результаты АСМ-исследований показали, что на поверхности образцов, облученных дозами $0.2-0.4 \mathrm{mC} / \mathrm{cm}^{2}$, максимальные диаметр и высота микровыступов достигают соответственно 120 и $30 \mathrm{~nm}$. Появление таких микроструктур на поверхности образцов не могло повлиять на их спектральные коэффициенты отражения в наблюдаемом в экспериментах диапазоне длин волн.

С ростом дозы облучения до $0.6 \mathrm{mC} / \mathrm{cm}^{2}$ (партия № 3 ) наблюдаются существенные количественные и качественные отличия в изменении структуры поверхности образцов (рис. 2). Если на образцах 1-го типа увеличиваются как количество, так и размеры микровыступов (рис. 2,a), то на образцах 2-го типа (рис. 2,b) их количество снижается, а размеры возрастают, достигая по высоте и диаметру соответственно 70 и $460 \mathrm{~nm}$ (на рис. 2, $b$ на них указывают стрелки). Образование таких микровыступов, по-видимому, связано с объединением газонаполненных пузырьков в приграничном слое стекла, находящемся под давлением пленки ITO.

Параметры, характеризующие изменения структуры поверхностей облученных образцов, приведены в Таблице. 

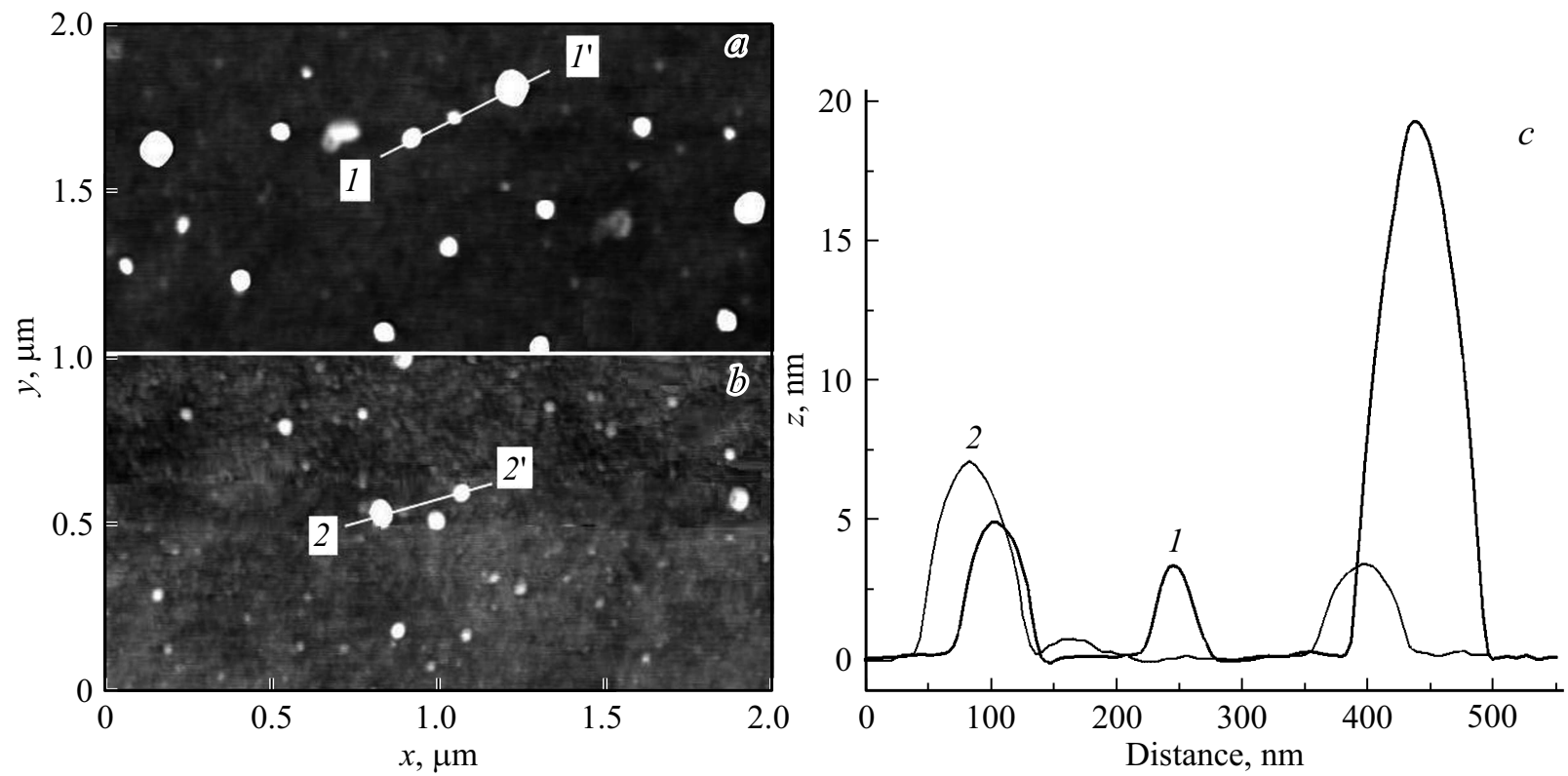

Рис. 1. АСМ-изображения облученных (дозой $0.2 \mathrm{mC} / \mathrm{cm}^{2}$ ) образцов 1-го $(a)$ и 2-го $(b)$ типа; $c-$ сечения кадров $a$ и $b$ соответственно вдоль линий $1-1$ ' (1) и 2-2'(2).
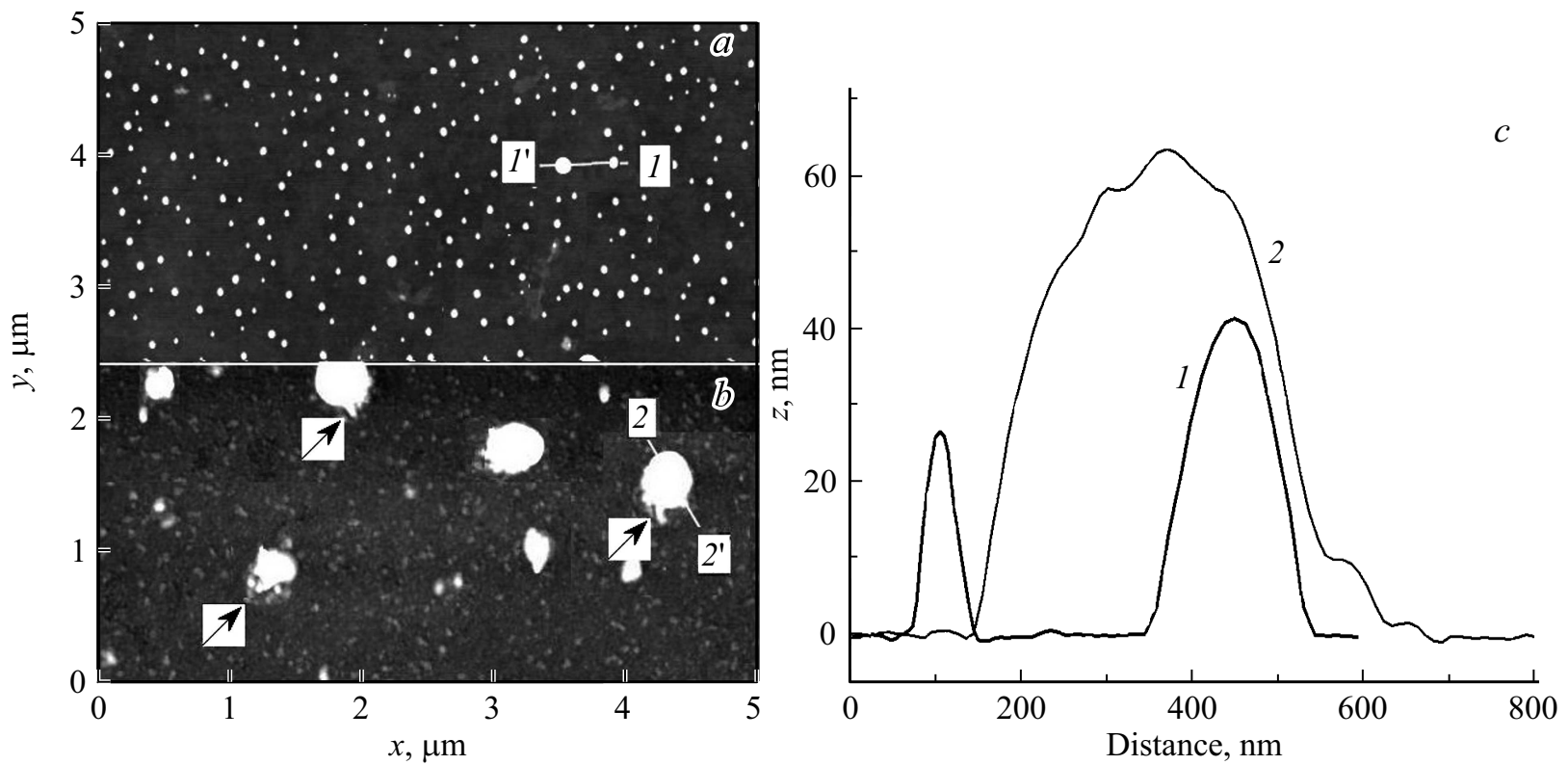

Рис. 2. АСМ-изображения облученных (дозой $0.6 \mathrm{mC} / \mathrm{cm}^{2}$ ) образцов 1-го $(a)$ и 2-го $(b)$ типа; $c-$ сечения кадров $a$ и $b$ вдоль линий $1-1^{\prime}(1)$ и 2-2' (2) соответственно.

В таблице $n_{1}, n_{2}-$ среднее число микровыступов высотой не менее $2 \mathrm{~nm}$ на единице поверхности образцов 1-го и 2-го типа; $h_{1}, h_{2}-$ средняя высота микровыступов на образцах 1-го и 2-го типа; $H_{1}, H_{2}$ и $D_{1}, D_{2}-$ соответственно максимальные значения высоты и диаметра основания микровыступов на образцах 1-го и 2-го типа.

При увеличении дозы до $1.0 \mathrm{mC} / \mathrm{cm}^{2}$ (партия №4) среднее количество микровыступов на поверхности образцов обоих типов практически совпадает с их средним количеством на образцах партии №3, а размеры микровыступов возрастают. Наличие на поверхности образцов 2-го типа микроструктур указанных в Таблице размеров может внести заметный вклад в изменение их отражательной способности.

Известно, что генерация носителей зарядов в облучаемом стекле, их миграция и локализация на соответствующих ловушках приводит к образованию электронных и дырочных ЦО. В стекле К208 локализованные состояния вблизи потолка валентной зоны сформированы орбиталями немостикового кислорода, а вблизи дна зоны 

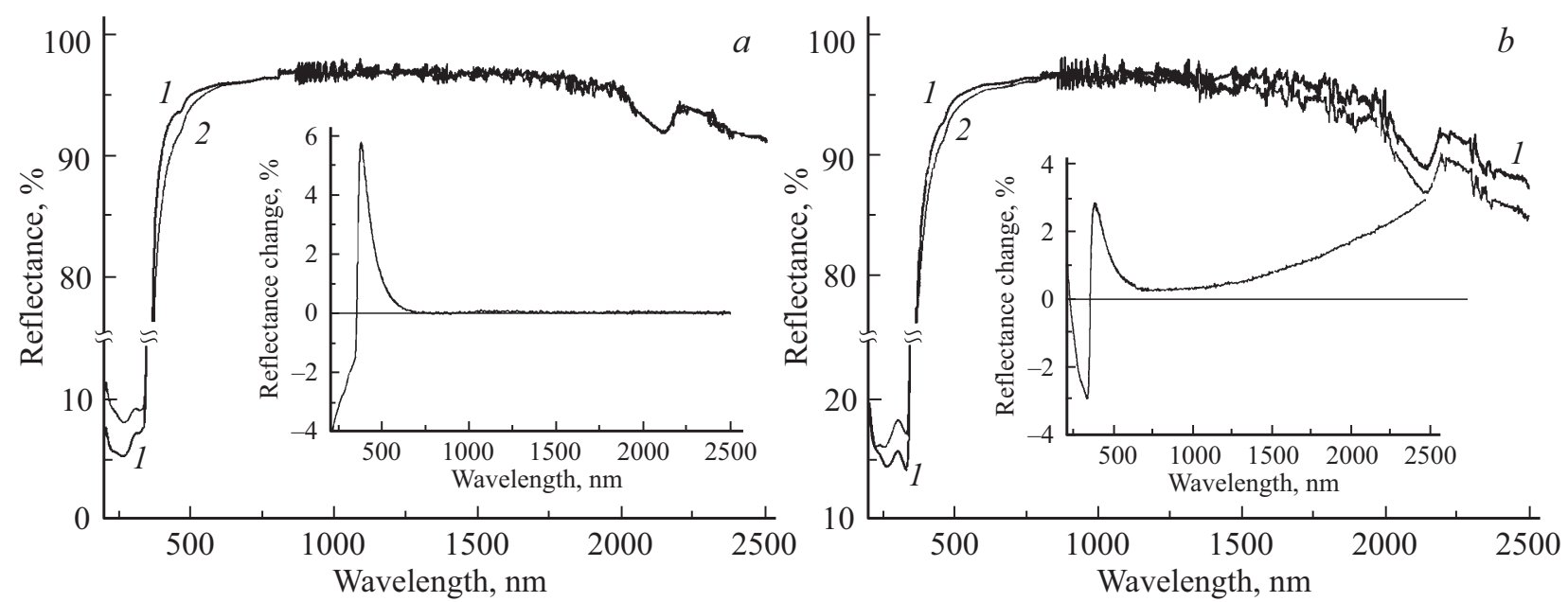

Рис. 3. Спектры отражения образцов 1-го $(a)$ и 2-го $(b)$ типа до $(1)$ и после $(2)$ облучения дозой $1.0 \mathrm{mC} / \mathrm{cm}^{2}($ на врезках разница спектров исходного и облученного образца).
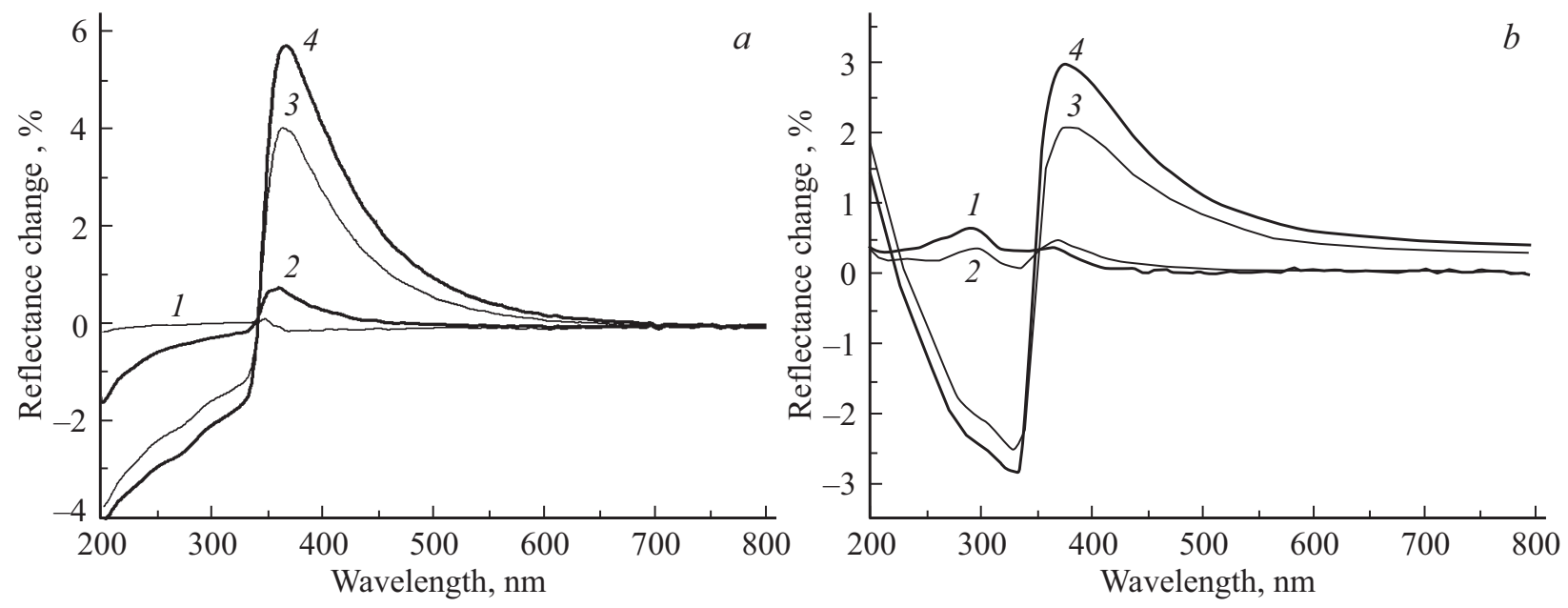

Рис. 4. Изменения спектров отражения образцов 1-го (a) и 2-го (b) типа, облученных дозами 0.2 (1), 0.4 (2), 0.6 (3), $1.0 \mathrm{mC} / \mathrm{cm}^{2}(4)$.

Параметры, характеризующие количество и размеры микровыступов на поверхности образцов

\begin{tabular}{c|c|c|c|l}
\hline $\begin{array}{c}\text { Номер } \\
\text { партии }\end{array}$ & $n_{1}\left(n_{2}\right), \mu \mathrm{m}^{-2}$ & $h_{1}\left(h_{2}\right), \mathrm{nm}$ & $H_{1}\left(H_{2}\right), \mathrm{nm}$ & $D_{1}\left(D_{2}\right), \mathrm{nm}$ \\
\hline 1 & $9.6(5.3)$ & $7.4(3.1)$ & $19(8)$ & $110(90)$ \\
2 & $14.3(6.9)$ & $14(10.6)$ & $28(21)$ & $120(110)$ \\
3 & $17.1(4.9)$ & $18(21)$ & $44(72)$ & $130(460)$ \\
4 & $16.8(4.3)$ & $24(27)$ & $70(98)$ & $210(600)$
\end{tabular}

проводимости - орбиталями натрия и калия. Повышенная радиационно-оптическая стойкость К208 обеспечивается наличием в его составе церия - элемента переменной валентности, который, в одной валентной форме $-\mathrm{Ce}^{3+}-$ является ловушкой для дырок, а в другой $-\mathrm{Ce}^{4+}-$ для электронов. При этом ионы Cе, являющиеся активными конкурентами, существующим в стекле ловушкам носителей заряда, не поглощают электромагнитное излучение в видимой части спектра.

На рис. 3 показаны изменения спектров отражения образцов 1-го (рис. 3,a) и 2-го типов (рис. 3,b) облученных дозой $1.0 \mathrm{mC} / \mathrm{cm}^{2}$ (партия № 4). Разница между спектрами исходных и облученных образцов, представленная на вставках в рисунки, показывает, что спектр отражения образца 1-го типа изменяется в основном в диапазоне длин волн 200-600 nm, а для образцов 2-го типа изменения охватывают всю наблюдаемую в экспериментах часть спектра.

Рис. 4 демонстрирует изменения спектров отражения образцов обоих типов из четырех партий в диапазоне длин волн 200-800 nm. Из этого рисунка видно, что в диапазоне 200-340 nm коэффициент отражения образцов 1-го типа (рис. 4, $a$ ) растет вместе с дозой облучения. Это объясняется увеличением показателя преломления стекла в облучаемом слое. 
Изменения спектров отражения образцов 2-го типа в диапазоне 200-340 nm (рис. 4, $b$ ) имеют более сложный характер зависимости от дозы. А именно, отражательная способность образцов, облученных дозами $0.2-0.4 \mathrm{mC} / \mathrm{cm}^{2}$, незначительно снизилась, а образцов, облученных дозами $0.6-1.0 \mathrm{mC} / \mathrm{cm}^{2}$, возросла в интервале $(230-340) \mathrm{nm}$, т.е. в более узком диапазоне, чем у образцов 1-го типа. Такие изменения обусловлены конкурирующими процессами, сопровождающими облучение образцов 2-го типа. С одной стороны, отражательная способность образца возрастает за счет процессов, протекающих в облучаемом слое стекла, а с другой снижается за счет изменений морфологии пленки ITO и генерации в нем дефектов.

Изменения спектров отражения образцов в диапазоне (350-500) nm обусловлено генерацией в стекле ЦО, количество которых растет вместе с поглощенной дозой. В стеклянной части образцов 2-го типа выделяется только часть начальной энергии протонов, поэтому и снижение их отражательной способности в указанном диапазоне меньше, чем у образцов 1-го типа.

\section{Выводы}

На основании исследования изменений характеристик стеклянных образцов со свободной поверхностью (образцы 1-го типа) и с нанесенной на нее пленкой ITO (образцы 2-го типа) за счет облучения протонами с энергиями $20 \mathrm{keV}$ при дозах от 0.2 до $1.0 \mathrm{mC} / \mathrm{cm}^{2}$ сделаны следующие выводы.

1. Изменения спектров отражения исследованных образцов в диапазоне длин волн $(200-2500) \mathrm{nm}$ обусловлены несколькими причинами: увеличением показателя преломления облучаемого стекла; накоплением в стекле и в пленке ITO (при ее наличии) центров поглощения; образованием на поверхности образцов 2-го типа газонаполненных микровыступов, высота и диаметр которых достигают соответственно 90 и $600 \mathrm{~nm}$.

2. Начиная с дозы облучения $0.6 \mathrm{mC} / \mathrm{cm}^{2}$, происходят значительные изменения спектров отражения образцов 1-го типа в диапазоне длин волн (200-600) nm и 2-го типа во всем исследованном диапазоне (200-2500) nm. Снижение отражательной способности образцов обоих типов в диапазоне (340-600) nm в основном обусловлено накоплением радиационных ЦО в стекле.

3. Отражательная способность в диапазоне (200-340) nm образцов 1-го типа возрастает вместе с дозой облучения, а образцов 2-го типа с увеличением дозы возрастает и снижается соответственно в диапазонах (230-340) nm и (200-230) nm.

4. Снижение отражательной способности образцов 2-го типа в диапазонах (200-230) и $(600-2500) \mathrm{nm}$ связано в основном с деградаций свойств пленки ITO. Следовательно, нанесение пленки ITO на зеркальные отражающие покрытия снижает их стойкость к воздействию протонов ГМП.

\section{Список литературы}

[1] Ferguson D.C., Wimberly S.C. // Proceed. 50th AIAA Aerospace Sci. Mtg. January, 2013. Nashville, Tennessee. AIAA 2013-0810. doi 10.2514/6.2013-810.

[2] Hirokazu Masui, Kazuhiro Toyoda, Mengu Cho // IEEE Trans. on Plasma Sci. 2008. V. 36. P. 2387-2394. doi 10.1109/TPS.2008.2003191.

[3] Cho M., Kawakita S., Nakamura M., et al. // J. Space. Rockets. 2005. V. 42. N 4. P. 740-748. doi 10.2514/1.6694.

[4] Ferguson D.C., Katz I. // IEEE Trans. Plasma Sci. 2015. V. 43. N 9. P. $3021-3026$.

[5] Хасаншин Р.Х., Новиков Л.С., Коровин С.Б. // Поверхность. Рентген., синхротрон. и нейтрон. исслед., 2015. № 1. C. 88-93; Khasanshin R.H., Novikov L.S., Korovin S.B. // J. Surf. Invest.: X-ray, Synchrotron and Neutron Tech. 2015. V. 9. N 1. P. 81-86. doi 10.1134/s1027451015010115

[6] Gedeon O., Zemek J., Jurek K. // J. Non-Crystalline Solids. 2007. V. 354. N 12-13. P. 1169-1171. doi 10.1016/j.jnoncrysol.2006.12.125.

[7] Meyza X., Goeuriot D., Guerret-Pi.court C., Tr.heux D., Fitting H.-J. // J. Appl. Phys. 2003. V. 94. N 8. P. 5384-5392. doi 10.1063/1.1613807

[8] Khasanshin R.H., Novikov L.S. // Advances in Space Res. 2016. V. 57. P. $2187-2195$.

[9] Хасаншин Р.Х., Новиков Л.С., Коровин С.Б. // Поверхность. Рентген., синхротрон. и нейтрон. исслед. 2017. № 9. C. 28-34. doi 10.7868/S0207352817090049; Khasanshin R.H., Novikov L.S., Korovin S.B. // Surf. Invest.: X-ray, Synchrotron and Neutron Tech. 2017. V. 11. N 5. P. 917-923. doi 10.1134/S102745101705007X

[10] Брунов В.С., Подсвиров О.А., Сидоров А.И., Чураев Д.В. // ЖТФ. 2014. Т. 84. В. 8. С. 112-117; Brunov V.S., Podsvirov O.A., Sidorov I. et al. Tech. Phys. 2014. V. 59. N 8. P. 1215-1219. doi 10.1134/S1063784214080088.

[11] Брунов В.С., Подсвиров О.А., Сидоров А.И., Просников М.A. // ЖТФ. 2014. Т. 84. В. 12. С. 126-131; Brunov V.S., Podsvirov O.A., Sidorov A.I., Prosnikov M.A. Tech. Phys. 2014. V. 59. N 12. P. $1863-1868$. doi 10.1134/S1063784214120032

[12] Крылов П.Н., Закирова Р.М., Федотова И.В. // ФТП. 2013. T. 47. B. 10. C. 1421-1424; Krylov P.N., Zakirova R.M., Fedotova I.V. // Semiconductors. 2013. V. 47. N 10. P. 1412-1415. doi 10.1134/S1063782613100175

[13] Амосова Л.П., Исаев М.В. // ЖТФ. 2014. Т. 84. В. 10 C. 127-132; Amosova L.P., Isaev M.V. // Tech. Phys. 2014. V. 59. P. 1545-1549. doi 10.1134/S1063784214100053

[14] Morgan D.V., Salehi A., Aliyu Y.H., Bunce R.W., Diskett D. // Thin Solid Films. 1995. V. 258. N 1-2. P. 283-285. doi 10.1016/0040-6090(94)06420-2

[15] Garrett H.B., Spitale G.S. // J. Spacecraft and Rockets. 1985. V. 22. N 3. P. $231-244$.

[16] Свечкин В.П., Савельев А.А., Соколова С.П., Бороздина O.B. // Космическая техника и технологии. 2017. № 2. B. 17. C. $99-107$.

[17] Kudlinski A., Quiquempois Y., Martinelli G. // Opt. Expr. 2005. V. 13. N 20. P. $8015-8024$.

[18] Doremus R.H. // Appl. Phys. Letter. 2005. V. 87. N 23. P. 232904-2. doi 10.1063/1.2140090

[19] Skuja L., Kajihara K., Hirano M., Saitoh A., Hosono H. // J. Non-Cryst. Sol. 2006. V. 352. P. 2297-2302. doi 10.1016/j.jnoncrysol.2006.01.101 
[20] Skuja L., Kajihara K, Hirano M., Hosono H. // Nuclear Instr. and Meth. in Phys. Res. B. 2008. V. 266. P. 2971-2975. doi 10.1016/j.nimb.2008.03.150

[21] Хасаншин Р.Х., Новиков Л.С. // Поверхность. Рентген., синхротрон. и нейтрон. исслед. 2018. № 11. С. 48-58. doi 10.1134/S0207352818110136; Khasanshin R.H., Novikov L.S. // J. Surf. Invest.: X-ray, Synchrotron and Neutron Tech. 2018. V. 12. N 6. P. 1088-1098. doi $10.1134 / \mathrm{S} 1027451018050452$

[22] Ollier N., Boizot B., Reynard B., Ghaleb D., Petite G. // J. Nucl. Mater. 2005. V. 340. N 2-3. P. 209-213. doi 10.1016/j.jnucmat.2004.11.011

[23] Zhang G.F., Wang T.S., Yang K.J., Chen L., Zhang L.M., Peng H.B., Yuan W., Tian F. // Nucl. Instr. Meth. B. 2013. V. 316. P. 218-221. doi 10.1016/j.nimb.2013.09.020

[24] Abbas A., Serruys Y., Ghaleb D., Delaye J.M. // Nucl. Instr. Meth. B. 2000. V. 166. P. 445-450. doi 10.1016/S0168583X(99)00695-3 